\title{
Preventive Medicine in Industry
}

\author{
N. H. COLLISSON
}

$\mathrm{O}^{\mathrm{c}}$ CCUPATIONAL HEALTH services virtually date from 1914, the year the Division of Occupational Health was created in the Public Health Service, so most of today's achievements can be chalked up as fruits of the past 50 years. Previously, occupational health had been studied by private physicians. It is said that Hippocrates (460-377 B.C.) recognized the dangers of certain crafts and practices, while Ramazzini (1633-1714), considered to be the father of industrial medicine, published a monumental text on occupational diseases. Throughout the 19 th century knowledge on occupational health was accumulated, certain legislation for the protection of health, including restrictions on materials and procedures, was passed, and child labor laws were enacted.

Not until the second decade of this century, however, did industry itself begin to assume substantial responsibility for the health of its workers on the job, with the establishment of the first significant industrial medical departments. In time the major U.S. companies established occupational health programs, instituting not only pre-employment examinations but also more complete examinations and studies of industrial workers, periodic followup examinations, and maintenance of valuable medical histories.

Recognition came, too, of the importance of emotional factors to an employee's health, and

Mr. Collisson is president and chairman of the board of Olin Mathieson Chemical Corporation. psychiatry was introduced in the factory. Progress has been made in the study of the causes of alcoholism and absenteeism and the frequent relation of both to mental health.

Workmen's compensation and group health insurance have helped to alleviate financial strain on employees caused by accidents or ill health. Meanwhile, the continuing improvement of standards of occupational health has been assisted by special journals, by the certification of occupational health services, and by improving the caliber of physicians through the American Board of Occupational Medicine. Hand-in-hand with its interest in occupational health, industry has intensified its drive for safety, and safety records have improved remarkably. The National Safety Council states: "Between 1912 and 1962, accidental work deaths per 100,000 population were reduced 67 percent, from 21 to 7 . In 1912, an estimated 18,000 to 21,000 workers' lives were lost while producing $\$ 100$ billion worth of gross national product. In 1962, in a work force double in size and producing nearly five times as much, there were only 13,700 work deaths."

The worker is safer on the job than away from it. In 1962, nearly 7 of 10 deaths and more than half of the injuries to workers oc. curred off the job. Today the American industrial employee is the best paid, most productive, and the safest employee in the world. With the advent of automation in one form or another, the mental agility of the worker is a must. His health therefore is more important than ever before. 
We still have a long way to go, but we might summarize the progress of occupational health activities this way. Fifty years ago, many of the problems were recognized. Since then, significant steps have been taken to correct the deficiencies. Now let us take a businessman's look at the economic advantages of an occupational health program.

\section{Business Values of Occupational Health}

Even today, some in the ranks of management doubt the value of an occupational health program. Others say that the trend toward increasing medical services in companies is a form of industrial socialism, that we are eroding the free enterprise system by encroaching upon the private physician's practice.

I take exception to these arguments. I say that we have legitimate reasons to foster occupational health programs. Moreover, they are good business. There is no question that we will see more rather than fewer broad occupational health activities in industry. As combined activities of the industrial physician, environmental health specialist, and safety engineer, occupational health programs will increasingly stress the prevention of illness and injury. Health maintenance is primarily the responsibility of the individual, but a good occupational health program is in the enlightened self-interest of the business.

In addition to the obvious benefits to the welfare of employees, a good occupational health program can help business in the following four ways.

To reduce the cost of workmen's compensation insurance. The rates of this insurance in general are based on the plant's actual experience, and the greater the number and severity of accidents, the higher the rates. A combined safety and occupational health program can help prevent accidents and reduce lost time by preventive action. While it is difficult to pinpoint the responsibility for workmen's compensation costs, it has been noted in the Olin organization that locations having the best occupational health and safety programs are also those with the lowest costs for workmen's compensation.

To reduce the cost of hospital and surgical insurance claims. In general, hospital and surgical insurance companies are nonprofit organizations, and the rate charged to the individual firm is determined by the actual claims. The greater the amount of the claims, the higher are the insurance premiums for the company.

To reduce absenteeism. Absenteeism plagues every plant. For the employee, absenteeism means lower earnings; for the industry, it means disturbance of the production team. The national annual cost of industrial absenteeism is measured in billions of dollars. In this area alone, a medical program which stresses prevention can make a tremendous contribution. It is estimated that personal health problems account for 10 times as many absences as those caused by inplant conditions. For this reason, it is easy to see why the total health of the employee is of great importance to the prudent employer.

To reduce labor turnover and increase efficiency. A good occupational health program is one factor in a safe and pleasant working environment which helps to keep employees in their jobs and to make them more efficient. Industry invests a tremendous amount of money in training each employee. This investment is completely lost when the employee leaves and the industry must undertake duplicate training of his replacement.

Data concerning these four points can be charted for a particular plant in relation to an industry or area average. For example, a study of our Pisgah Forest, N.C., plant revealed considerable declines during a 20-year period in workmen's compensation rates, group insurance rates, lost-time cases, absenteeism, accident frequency and severity rates, and labor turnover. The plant's ratings also compared favorably with the North Carolina State average and the U.S. average. This marked change occurred during a period of increased emphasis on occupational health and safety programs. The Blue Cross-Blue Shield experience at this plant during the period 1952-62 demonstrates a tangible monetary return from the investment in the medical program (fig. 1).

When the occupational health program was started at the Pisgah Forest plant, the monetary saving was low because our experience gener- 
ally equaled the State group average on which the group health insurance premiums are based. However, in 1962, as the long-range effects of the medical program were experienced, the plant was saved about $\$ 65,000$ in employees' Blue Cross-Blue Shield claims (fig. 2). This sum is based on comparison with predicted actuarial estimates.

During the 10-year period the number of claims filed by our employees increased markedly. From this fact we can assume that employees were using their Blue Cross-Blue Shield plans freely, but the dollar amount per claim grew progressively smaller because they became accustomed to attending to their physical and emotional defects at a time when they can be corrected easily and inexpensively.

A good occupational health program can also help achieve these less tangible objectives :

1. Creation of a good work environment. This is an employee relations factor that influences the worker's attitude toward the plant and its management.

2. Persuade the employee that management is sincere in its concern for him and thereby promote mutual respect between employee and management.

3. Convince the employee that his job is important because of management's concern with his health and safety. It is now a well-established doctrine that an employee's productivity, the quality of his production, and his receptivity to management are largely determined by his morale and basic attitude.

4. Increase the useful span of years of both

Figure 1. Blue Cross-Blue Shield insurance claims cost, North Carolina State group average and Pisgah Forest plant of Olin Mathieson, 1952-62

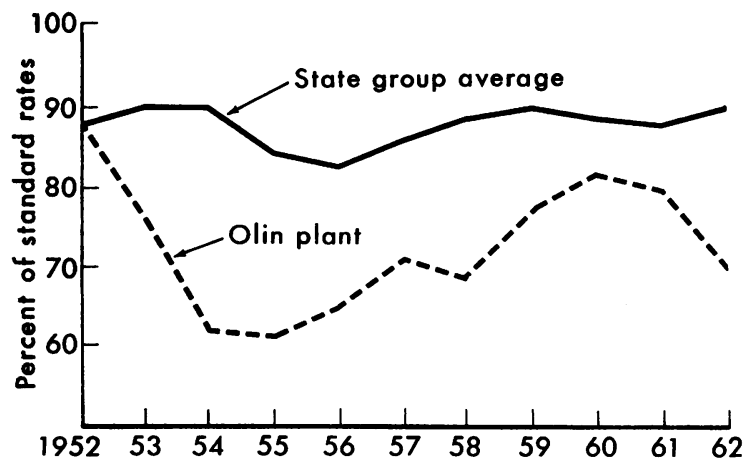

Figure 2. Annual savings in Blue Cross-Blue Shield policy claims, Pisgah Forest, N.C., plant of Olin Mathieson, 1952-62

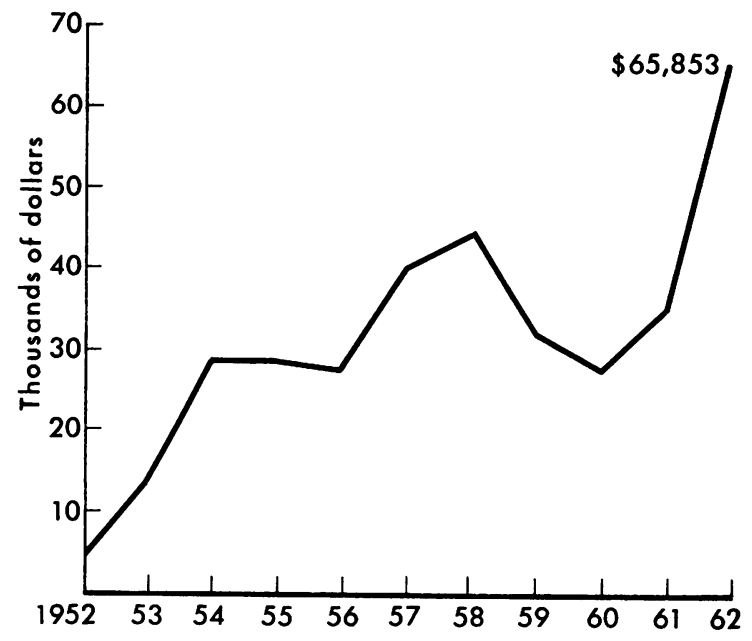

worker and management personnel. This means greater earning power for the worker and a longer period of usefulness to the corporation.

\section{Private Physicians and Industrial Medicine}

Let us finally dispense with the idea that plant physicians compete with private physicians. Industrial medical departments provide a wider range of medical services than ever before, but primarily they practice preventive medicine. For example, if an influenza epidemic threatens, it is plainly good business to provide our employees with inoculations in order to prevent waves of absenteeism, usually at least 1 week off for those afflicted. We know that most of our employees would never see a private physician for preventive shots-they call one only after contracting the illness.

Although we encourage our employees to have their own private physicians, the unavoidable fact is that many people in the nation do not see a physician regularly. Therefore, in the course of periodic examinations, the company physician frequently discovers conditions that a private physician would never have the opportunity to see. But normally the private physician benefits, for the company practitioner usually refers the employee to his family physician or to a specialist for treatment. The industrial physician can frequently be called a coordinator 


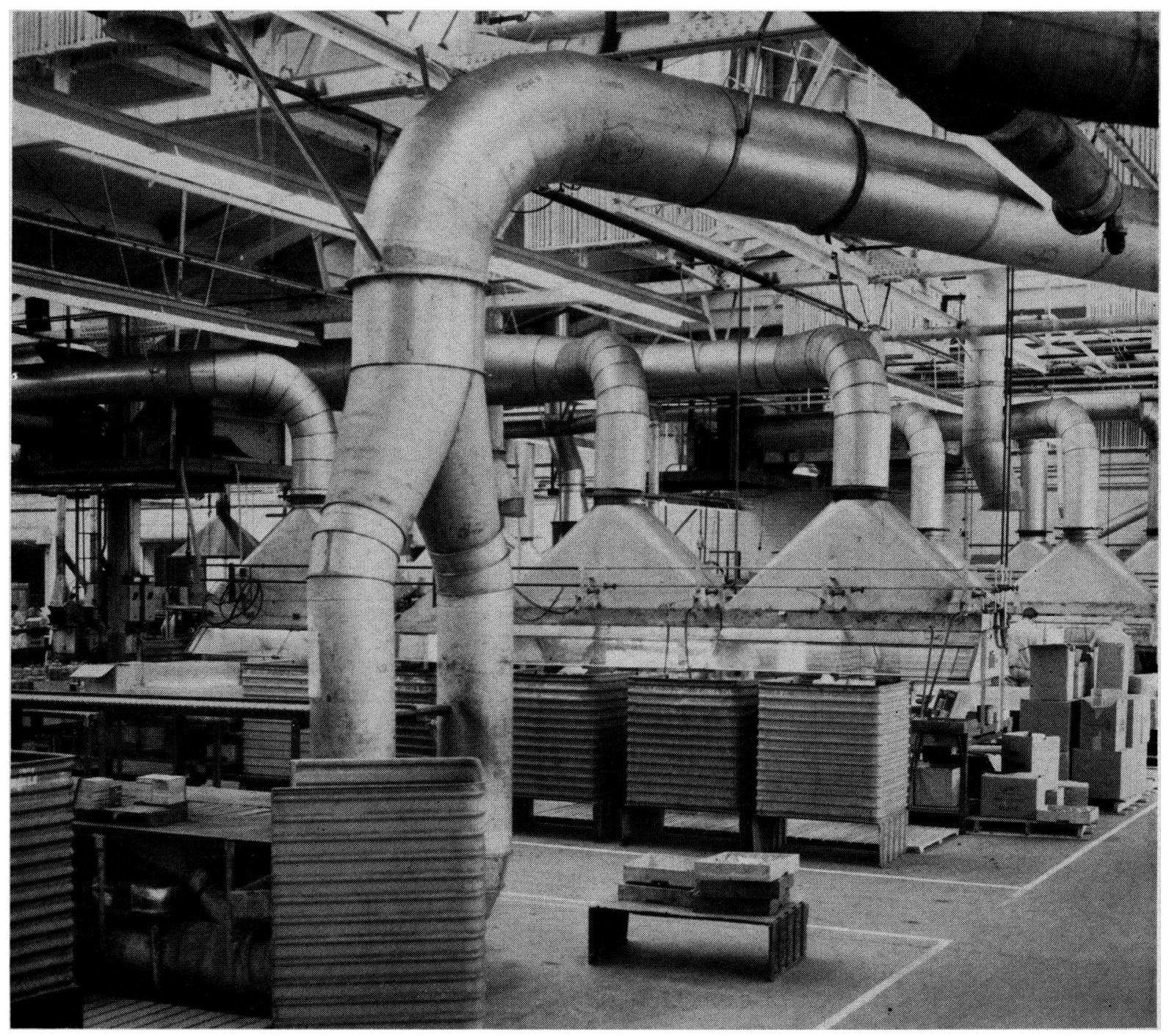

A storage battery assembly room with a good ventilation system

of medical services. The traditions and customs of private medical practice do not allow physicians to solicit patients. But the industrial physician is in a position to observe employees' health. He examines, counsels, and refers employees to private physicians for definitive care.

\section{Role of the Environmental Hygienist}

The environmental hygienist works closely with the plant physician in an occupational health program. His knowledge, skills, and activities are devoted primarily to the prevention of illness which might arise, directly or in- directly, from the conduct of the business. He serves industry in a variety of ways, but he is particularly valuable as a member of the occupational health team in efforts to control the purity of the working environment in order to make it safe for employees and to control the purity of products to insure that they are safe for public consumption.

The problems of environmental hygiene can be divided into these areas : atmospheric purity, noise, illumination, heat, and radioactivity. The environmental hygienist reviews both products and plant operations to determine if potential hazards exist and consults with medical department personnel. At Olin, our cor- 
porate environmental hygienist is a member of the medical director's staff, and he is an important member of the occupational health team.

\section{Role of the Safety Engineer}

The safety engineer teams up with the environmental hygienist and the plant physician in the drive to eliminate hazards and to educate employees in good safety and health practices. The safety engineer is interested in the safety of the entire physical environment, including facilities and equipment, as well as safe working procedures. His knowledge and objectives supplement those of the physician and environmental hygienist.

Earlier, I quoted figures from the National Safety Council showing that the industrial worker is far safer today than he was in 1914 and that he is much safer on the job than off the job. Throughout Olin, an intensive safety program has helped to reduce the total number of disabling injuries from 302 in 1959 to 128 in 1963. During the same period, the number of disabling injuries per million man-hours worked dropped from 4.38 to 1.90 . The frequency of disabling injury for all industry in 1963 was 6.19 .

\section{Advantages of the Company Medical Team}

The company physician, teamed with personnel skilled in environmental hygiene and safety, is in a position to make recommestations to management regarding the control of environmental factors. Because of his knowledge of an employee's working environment and his medical history, the company physician frequently has an advantage over the private practitioner in making a quick and correct diagnosis of the illness.

An example of this was the case of an employee who reported to his private physician with fatigue and stomach cramps and stated that he worked with paints. The physician tentatively diagnosed the condition as lead poisoning but called the plant medical group and learned that, while the employee did work with paint, it did not contain lead and that there was no other lead exposure in the em- ployee's environment. A further look into the employee's complaints revealed a nonoccupational illness.

\section{The Fourth Human Right}

Tremendous advances in medical science have raised the average life expectancy from 40 years a half century ago to 70 years or more. But merely staying alive longer may be of doubtful merit if physical and mental processes have declined seriously-or just as bad-if the contributions one is allowed to make to business and society are all but finished in later years. Much of man's physical equipment was designed to last for a lifetime of only 40 years or so, so that by age 70 he may have lost much of the health and energy required to live a fruitful life.

The need for and right to the essentials of food, shelter, and clothing have been well established. We also need to recognize health as a fourth human need and right. The challenge to the medical profession is to come up with ideas and procedures to insure health through private resources rather than waiting for government to come up with ideas and plans to meet the need. If the medical profession meets this challenge successfully in the years to come, our citizens at ages 65 and 70 will possesss the health and vitality to make use of the years that have been added to their lifespan.

As the medical profession takes up this challenge, we in business must do our part. I have always maintained that there is no conflict of interest between what management wants from occupational health programs and what the worker wants and needs. The health of employees is of mutual interest. But we in management must, in cooperation with the medical profession, keep pace with the times and be alert to the important health and social needs of employees. In addition to providing better health for senior citizens, we must counsel them and help them to lead interesting, productive, and enjoyable lives after retirement.

To sum up, the challenge is for the medical profession and business leaders to join in an effort to make it possible for a person to have, not solely more years of life, but more years of meaningful living. 